\title{
UV Enhanced Oxygen Response Resistance Ratio of ZnO Prepared by Thermally Oxidized Zn on Sapphire Substrate
}

\author{
Cheng-Chang Yu, ${ }^{1}$ Yu-Ting Hsu, ${ }^{1}$ Wen-How Lan, ${ }^{2}$ Ming-Chang Shih, ${ }^{2}$ Jin-Hua Hong, \\ Kai-Feng Huang, ${ }^{1}$ and Chien-Jung Huang ${ }^{3}$ \\ ${ }^{1}$ Department of Electrophysics, National Chiao Tung University, Hsinchu 30010, Taiwan \\ ${ }^{2}$ Department of Electrical Engineering, National University of Kaohsiung, Kaohsiung 81148, Taiwan \\ ${ }^{3}$ Department of Applied Physics, National University of Kaohsiung, Kaohsiung 81148, Taiwan \\ Correspondence should be addressed to Wen-How Lan; whlan@nuk.edu.tw
}

Received 14 September 2013; Revised 10 October 2013; Accepted 10 October 2013

Academic Editor: Liang-Wen Ji

Copyright (C) 2013 Cheng-Chang Yu et al. This is an open access article distributed under the Creative Commons Attribution License, which permits unrestricted use, distribution, and reproduction in any medium, provided the original work is properly cited.

\begin{abstract}
$\mathrm{ZnO}$ thin film was fabricated by thermally oxidized $\mathrm{Zn}$ at $600^{\circ} \mathrm{C}$ for $1 \mathrm{~h}$. A surface containing nanostructured dumbbell and lines was observed by scanning electron microscope (SEM). The $\mathrm{ZnO}$ resistor device was formed after the following Ti/Au metallization. The device resistance was characterized at different oxygen pressure environment in the dark and under ultraviolet (UV) light illumination coming from the mercury lamp with a short pass filter. The resistance increases with the increase of oxygen pressure. The resistance decreases and response increases with the increase of light intensity. Models considering the barrier height variation caused by the adsorbed oxygen related species were used to explain these results. The UV light illumination technology shows an effective method to enhance the detection response for this $\mathrm{ZnO}$ resistor oxygen sensor.
\end{abstract}

\section{Introduction}

In the past few years, the wide band gap material zinc oxide ( $\mathrm{ZnO})$ shows its abilities in many applications. Devices such as field emission device [1], surface acoustic wave device [2], photo diode [3], light emitting diodes [4], solar cells [5], and gas sensors [6-8] were studied. In the gas sensing applications, nanostructured $\mathrm{ZnO}$ with high surface-volumeratio properties shows the promotive performance $[9,10]$.

In studies of sensor performance, higher operation temperature may improve the sensor response performance in some certain conditions $[10,11]$. However, as device operated in the high temperature, response variation and device degradation can be observed also [11, 12].

As the sensing property for some oxide-based sensors changes under light illumination [13] and the $\mathrm{ZnO}$ is a wide band gap photodetector, the conductivity varies under UV light illumination [14-18]. As the oxidation of $\mathrm{Zn}$ metal in atmosphere to form the $\mathrm{ZnO}$ thin film is a simple method to achieve $\mathrm{ZnO}$ thin film [19-21] it is interesting to study such $\mathrm{ZnO}$ thin film sensing behaviour under UV illumination.
In our previous study, less response time was characterized for such $\mathrm{ZnO}$ oxygen $\left(\mathrm{O}_{2}\right)$ gas sensing characteristics under UV light illumination. In this paper, we study the effect of sensing response resistance ratio difference for $\mathrm{ZnO} \mathrm{O}_{2}$ sensor under UV light illumination.

\section{Materials and Methods}

In the fabrication of $\mathrm{ZnO}$, the $\mathrm{Zn}$ thin film was deposited first on c-plane sapphire substrate by thermal evaporation method from $\mathrm{Zn}$ chunk (5N, Tanaka) in vacuum chamber. The as-deposited $\mathrm{Zn}$ film with film thickness $510 \mathrm{~nm}$ shows gray-white color. After Zn deposition, the sample was then transferred to a $600^{\circ} \mathrm{C}$ furnace slowly in one hour to achieve the $\mathrm{ZnO}$ structure. The measured film thickness becomes $716 \mathrm{~nm}$. With standard photolithography lift-off process, the $\mathrm{Ti} / \mathrm{Au}(20 \mathrm{~nm} / 300 \mathrm{~nm})$ was formed on the film. Followed by a $20 \mathrm{~min}, 150^{\circ} \mathrm{C}$ thermal process in nitrogen environment, the ohmic contact was formed and the $\mathrm{ZnO}$ resistor structure was fabricated. The surface morphology of the film was 


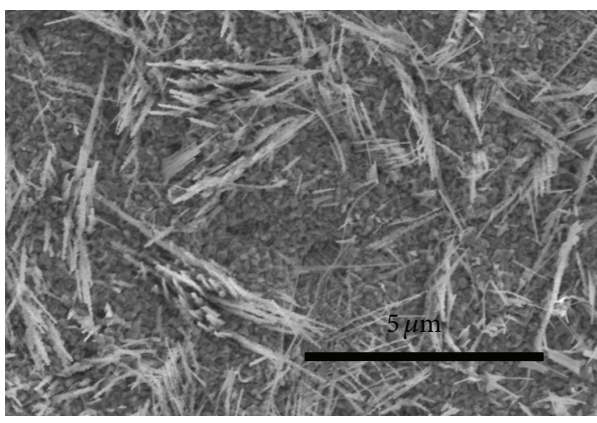

(a)

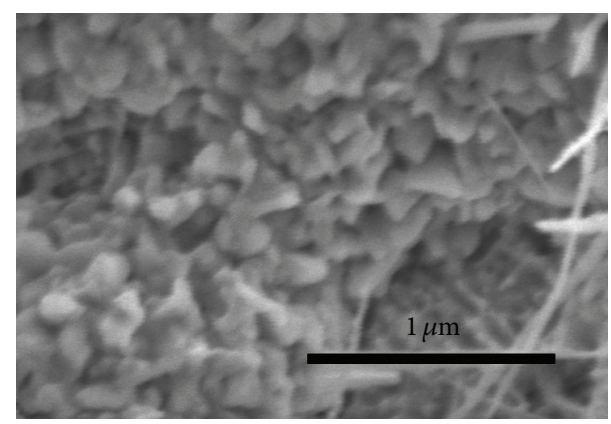

(b)

FIGURE 1: SEM surface morphology of the $\mathrm{ZnO}$ thin film at (a) 10,000x and (b) 50,000x magnifications.

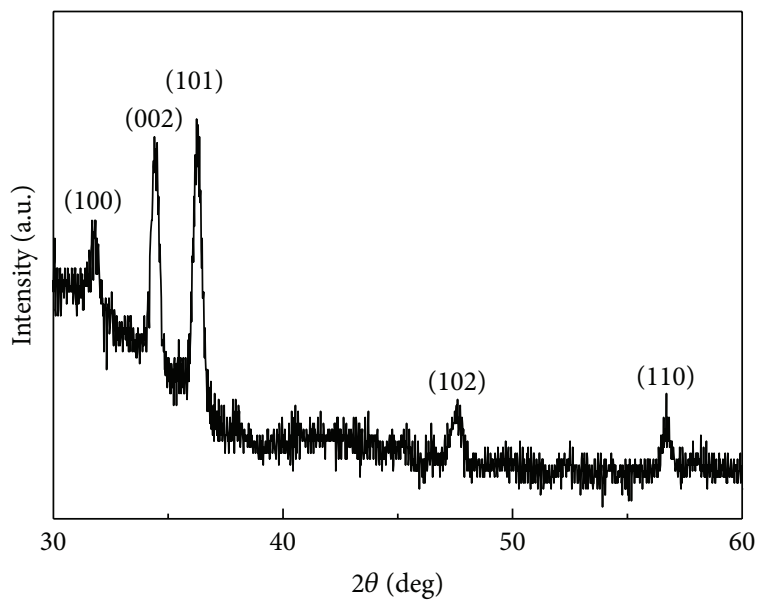

FIGURE 2: XRD spectrum for the $\mathrm{ZnO}$ thin film.

studied using scanning electron microscopy (SEM, Hitachi $\mathrm{S}-4300 \mathrm{~N})$. The crystalline structure was obtained by X-ray diffraction (XRD, Bruker D8) with $\mathrm{Cu} \mathrm{K} \alpha$ radiation. For the resistance measurement, the $\mathrm{ZnO}$ resistor device was put in a vacuum chamber with a diffusion pump. Ion gauge and Pirani gauge were used for the background gas sensing and pressure control. After pumping the vacuum system with background pressure less than $10^{-4}$ Torr. $\mathrm{O}_{2}$ gas was then introduced to the chamber with different pressure values. With proper valve control, the pressure reached a stable value in less than $30 \mathrm{~s}$. In the $\mathrm{O}_{2}$ extracting process, the pressure reached less than $10^{-4}$ Torr in around $120 \mathrm{~s}$. The resistance of the device was taken in Keithley 2400 multimeter. The film thickness was analyzed by Tencor Alpha Step 500. In the UV light illumination procedure, the dominant wavelength is $253.7 \mathrm{~nm}$ and comes from one $50 \mathrm{~W}$ mercury lamp with a short pass filter. An intensity reductor was used to control the light intensities.

\section{Results and Discussion}

Figure 1 shows the surface morphology characterized by SEM for the $\mathrm{ZnO}$ film at (a) 10,000x and (b) $50,000 \mathrm{x}$ magnifications. The surface shows a smooth ball structure

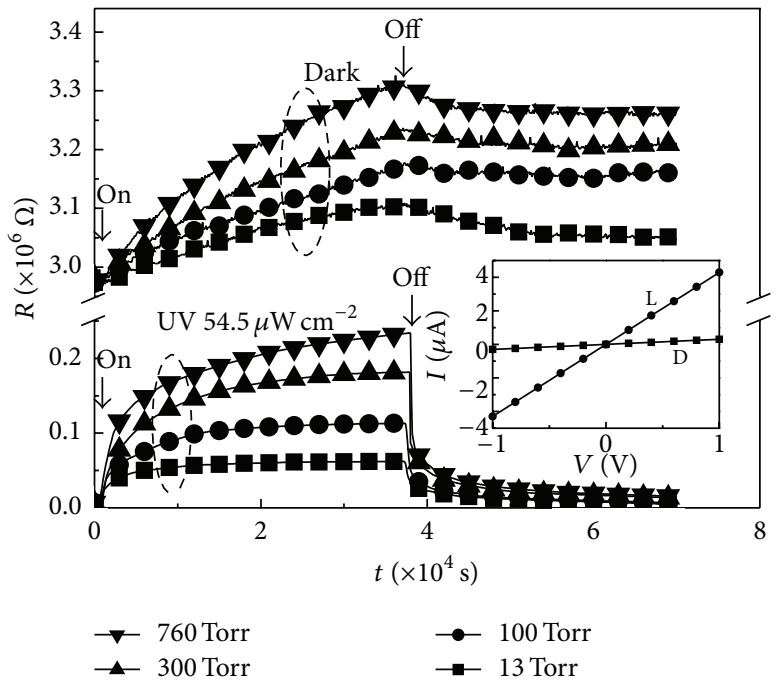

FIGURE 3: Resistance transients of $\mathrm{ZnO}$ resistor device measured at different $\mathrm{O}_{2}$ pressures under $54.5 \mu \mathrm{W} \mathrm{cm}{ }^{-2} \mathrm{UV}$ light illumination. The inset shows the current-voltage behavior in the dark (D) and under UV light illumination (L) at 760 Torr.

on bottom with diameter around $200 \mathrm{~nm}$ and some locally distributed nanolines can be observed.

The XRD spectrum of the $\mathrm{ZnO}$ film was shown in Figure 2. All the peaks correspond to the hexagonal $\mathrm{ZnO}$ structure (JCPDS 36-1451) and no obvious Zn correlated peak [20] can be observed. The intensified (002) and (101) peak can be observed also for other $\mathrm{Zn}$ thermally oxidized $\mathrm{ZnO}$ films $[20,21]$.

Figure 3 shows the resistance $(R)$ transients of $\mathrm{ZnO}$ resistor measured at different $\mathrm{O}_{2}$ pressures in darkness and under $54.5 \mu \mathrm{W} \mathrm{cm}{ }^{-2} \mathrm{UV}$ light illumination. And a symmetrical current-voltage $(I-V)$ behavior in the dark (D) and with UV light illumination (L) was shown in the inset. From Figure 3, in the $\mathrm{O}_{2}$ introduced region $\left(\mathrm{O}_{2}\right.$ on), the resistance increases slowly and reaches stable values. In the $\mathrm{O}_{2}$ evacuation process $\left(\mathrm{O}_{2}\right.$ off $)$, the resistance decreases slowly and reaches a certain value. The resistance increases as of $\mathrm{O}_{2}$ pressure increases.

Figure 4 shows the device resistance measured at different $\mathrm{O}_{2}$ pressures (a) in darkness (dark) and under UV light 


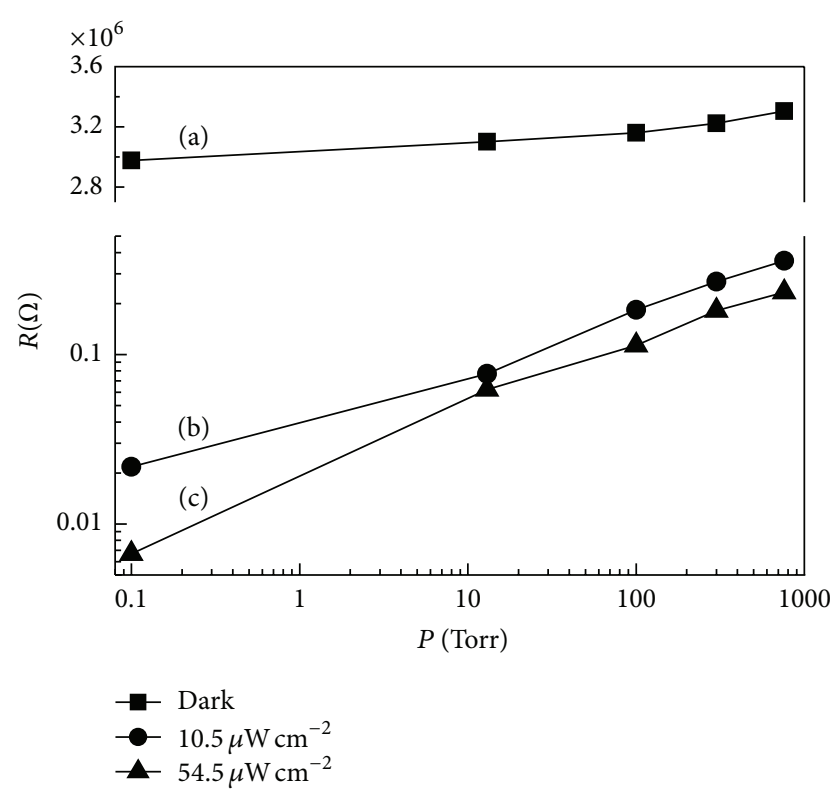

FIGURE 4: Resistance of the $\mathrm{ZnO}$ resistor device measured at different $\mathrm{O}_{2}$ pressures (a) in darkness (dark) and under (b) $10.5 \mu \mathrm{W} \mathrm{cm} \mathrm{cm}^{-2}$ and (c) $54.5 \mu \mathrm{W} \mathrm{cm}$ cm $^{-2} \mathrm{UV}$ light illumination.

illumination with power densities (b) $10.5 \mu \mathrm{W} \mathrm{cm}{ }^{-2}$ and (c) $54.5 \mu \mathrm{W} \mathrm{cm}{ }^{-2}$, respectively. The resistance increases with the increase of $\mathrm{O}_{2}$ pressure. The resistance decreases with the introduction of UV light illumination. With more carriers in the structure after UV light illumination, resistance decrease for the UV light illuminated $\mathrm{ZnO}$ film can be expected. Although the resistance decrease may be a worse effect for the sensor operation, the extension of resistance ratio can be observed in Figures 4(b) and 4(c).

If we take the resistance at 0.1 Torr, that is, the minimum resistance as the referenced resistance $R_{0}$ in each condition, the relative response resistance ratio (RR) can be defined as

$$
\mathrm{RR}=\frac{R_{P}}{R_{0}},
$$

where $R_{P}$ is the corresponding resistance at a certain pressure. Figure 5 shows the device resistance ratio measured at different $\mathrm{O}_{2}$ pressures in darkness (dark) and under UV light illumination with power densities $10.5 \mu \mathrm{W} \mathrm{cm}{ }^{-2}$ and $54.4 \mu \mathrm{W} / \mathrm{cm}^{-2}$. High resistance ratio can be observed for device under UV illumination.

For the $\mathrm{ZnO}$ gas sensors in $\mathrm{O}_{2}$ environment without $\mathrm{UV}$ light illumination, a chemisorption mechanism on the sensor surface can be described as [22]

$$
\mathrm{O}_{2}(\mathrm{~g})+\mathrm{e}^{-} \longrightarrow \mathrm{O}_{2}^{-} \text {(ads) }
$$

where (g) and (ads) represent the gas phase and adsorbed species, respectively. For the $\mathrm{ZnO}$ thin film resistor after the introduction of $\mathrm{O}_{2}$ gas, the adsorbed oxygen species $\mathrm{O}_{2}{ }^{-}$(ads) may accumulate around the grain boundary and cause more electron to be trapped [23, 24]. Figure 6 shows the schematic band structure drawing for the $\mathrm{ZnO}$ resistor

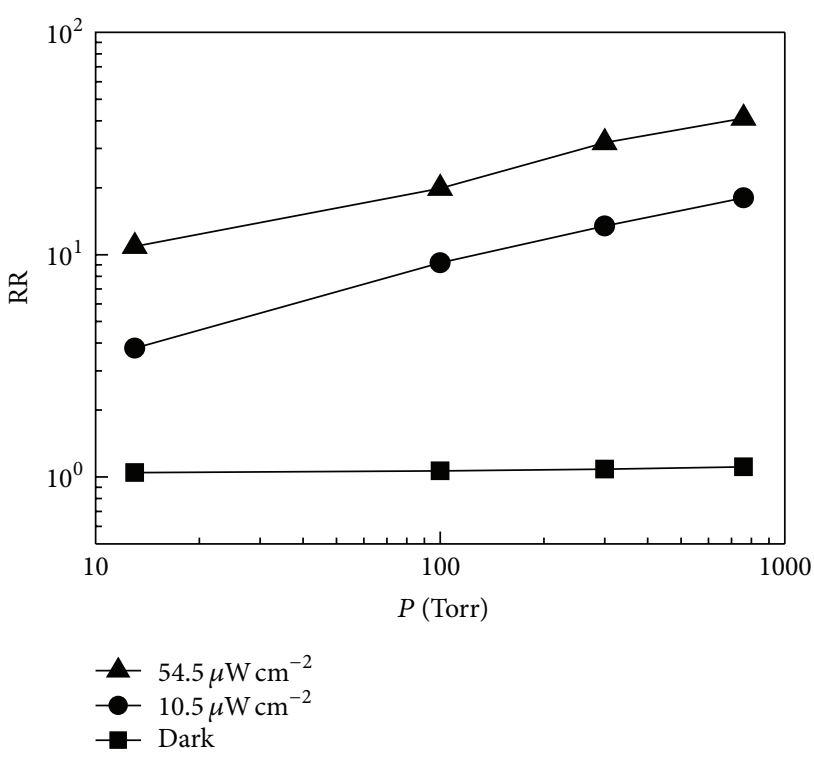

Figure 5: Relative resistance ratio of the $\mathrm{ZnO}$ resistor device at different $\mathrm{O}_{2}$ pressures in the dark (dark) and under UV light illumination with power densities $10.5 \mu \mathrm{W} \mathrm{cm}{ }^{-2}$ and $54.4 \mu \mathrm{W} / \mathrm{cm}^{-2}$.

across the grain boundary. The $E_{C}, E_{V}, E_{F}$, and $V_{B}$ represent the conduction band, valance band, Fermi level, and interface barrier height, respectively [20]. For Figure 6(a), in case of low $\mathrm{O}_{2}$ pressure in the dark, the adsorbed oxygen species may cause barrier bending upward slightly by trapping electron. With higher $\mathrm{O}_{2}$ pressure, as shown in Figure 5(b), more adsorbed oxygen species cause the increasing of barrier height and the resistance increases. The behavior of resistance increases with $\mathrm{O}_{2}$ pressure increasing can be observed in Figure 6(a). The variant resistance range was controlled by the pass through ability (labeled "1") of the electron in this case.

For device under UV illumination, as shown in Figures 4(b) and 4(c), the resistance decrease can be observed. With higher light intensity, more resistance reduction can be observed. Besides, the degree of resistance reduction is less for device operated at high $\mathrm{O}_{2}$ pressure under the same UV light intensity. As the UV photon energy $(4.9 \mathrm{eV})$ is higher than the band gap of $\mathrm{ZnO}(3.3 \mathrm{eV})$, electron-hole pairs will be generated. Figures 6(c) and 6(d) show the photogenerated electron-hole pair (labeled "2") around the grain boundary. With more carriers, resistance reduction can be expected. Besides, on the way to the electrode, hole accumulated in the grain boundary due to the band bending across the grain boundary. These holes may react with the negatively charged adsorbed oxygen species according to the following reaction [15]:

$$
\mathrm{O}_{2}{ }^{-}(\mathrm{ads})+\mathrm{h}^{+}(h v) \longrightarrow \mathrm{O}_{2}(\mathrm{~g}),
$$

where $h v$ implies that the reaction is under illumination. As a result of the above reaction, under the reaction with hole (labeled 3), the adsorbed oxygen species may desorb to oxygen molecules. Compared to the crystalline $\mathrm{ZnO}$ [15], as shown in the figure, the localization of hole in grain boundary in the polycrystalline $\mathrm{ZnO}$ is more efficient. Thus the reaction 
(a)

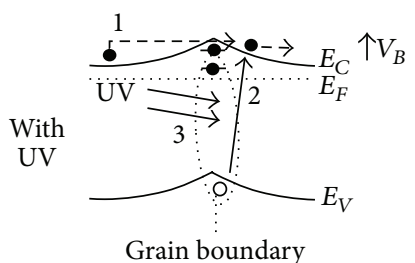

(c)

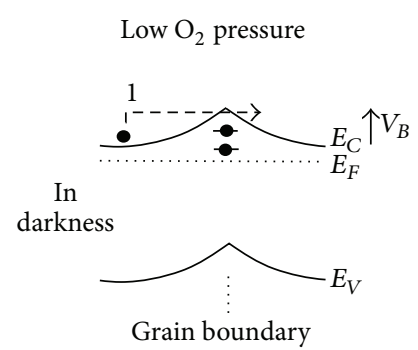

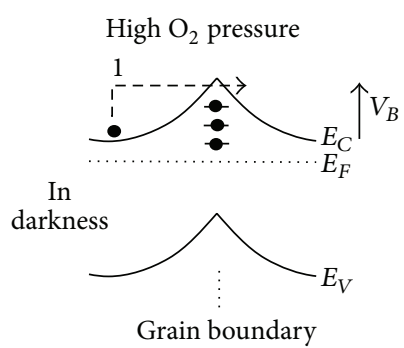

(b)

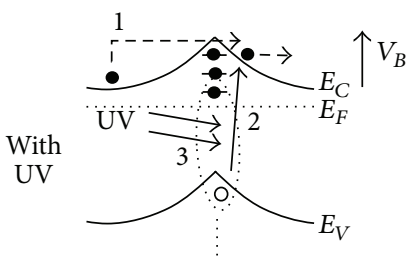

Grain boundary

(d)
FIGURE 6: Band structure of polycrystalline $\mathrm{ZnO}$ across the grain boundary in darkness and under UV light illumination at low and high $\mathrm{O}_{2}$ pressure. The electron (•)-hole (o) pair may be generated under the illumination with photon energy higher than the band gap.

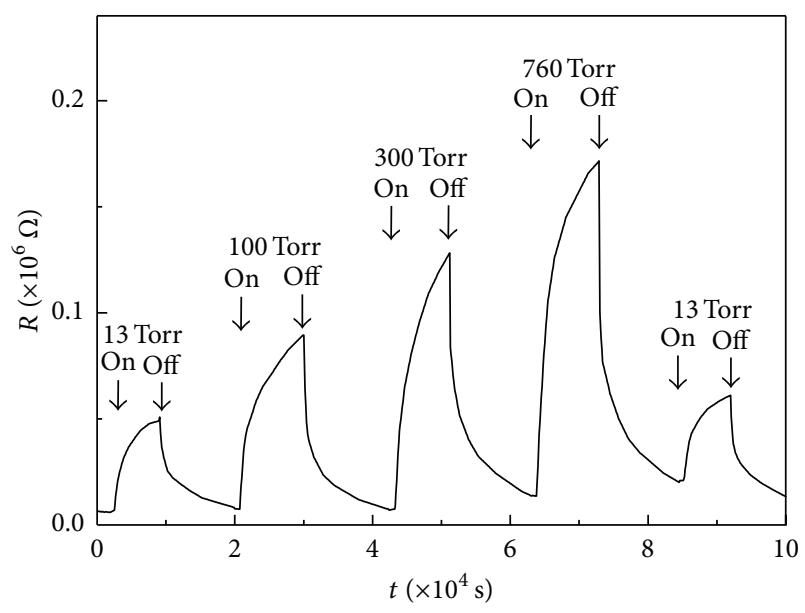

FIgURE 7: Dynamic response of the $\mathrm{ZnO}$ resistor at different $\mathrm{O}_{2}$ pressures under $54.5 \mu \mathrm{W} \mathrm{cm} \mathrm{cm}^{-2} \mathrm{UV}$ light illumination.

is much more efficient. The barrier height and depletion width will be reduced both in this case by the elimination of adsorbed oxygen species. In case of low $\mathrm{O}_{2}$ pressure, as shown in Figure 6(c), the adsorbed $\mathrm{O}_{2}$ species quantity may be small and the reduction of barrier is significant. More carriers can then go through this reduced barrier. The resistance reduction for device operated in low $\mathrm{O}_{2}$ pressure under UV light illumination is more efficient. In case of high $\mathrm{O}_{2}$ pressure, as shown in Figure 6(d), the barrier height may be reduced a little as the adsorbed oxygen species quantity is large.

For further understanding of the reproduced capability, the resistor was measured under stable $54.5 \mu \mathrm{W} \mathrm{cm}{ }^{-2} \mathrm{UV}$ light illumination at different $\mathrm{O}_{2}$ pressure levels. Figure 7 shows the resistance measured from low $\mathrm{O}_{2}$ pressure to high $\mathrm{O}_{2}$ pressure and back to low pressure conditions. At higher $\mathrm{O}_{2}$ pressure, with more adsorbed oxygen species, more recovery time is needed for the device to reach the original resistance value. From Figure 7, we also observed that the resistance increatment for the second low pressure (13 Torr) cycle is similar to the first cycle. This implies that this $\mathrm{ZnO}$ resistor can operate under stable UV light illumination. Although there may be some defect-related conduction for $\mathrm{ZnO}$ under light illumination, a repeated and stable operation can be observed in this resistor device. The UV-light illumination shows the ability in extending the response resistance ratio for the thermally oxidized $\mathrm{ZnO}$ gas sensor.

\section{Conclusion}

In conclusion, the $\mathrm{ZnO}$ resistor gas sensor device was fabricated by the oxidation of $\mathrm{Zn}$ metal on c-plane sapphire substrate. Device current-voltage behavior in the dark and under UV illuminations was studied. The resistance reduction and relative response increatment can be observed for device under UV illumination. Band bending and oxygen related gas species adsorption/desorption models with accumulated hole around grain boundary were used to explain the efficient resistance ratio variance. The UV light illumination shows an primitive efficient method to increase the resistance ratio of polycrystalline $\mathrm{ZnO}$ coming from the thermal oxidation of Zn metal.

\section{References}

[1] Q. Ahsanulhaq, J. H. Kim, and Y. B. Hahn, "Controlled selective growth of $\mathrm{ZnO}$ nanorod arrays and their field emission properties," Nanotechnology, vol. 18, no. 48, Article ID 485307, 2007.

[2] W.-C. Shih and R.-C. Huang, "Fabrication of high frequency $\mathrm{ZnO}$ thin film SAW devices on silicon substrate with a diamond-like carbon buffer layer using RF magnetron sputtering," Vacuum, vol. 83, no. 3, pp. 675-678, 2008.

[3] S. J. Young, L. W. Ji, S. J. Chang et al., "ZnO-based MIS photodetectors," Sensors and Actuators A, vol. 141, no. 1, pp. 225-229, 2008.

[4] J. J. Hassan, M. A. Mahdi, A. Ramizy, H. A. Hassan, and Z. Hassan, "Fabrication and characterization of $\mathrm{ZnO}$ nanorods/p$6 \mathrm{H}-\mathrm{SiC}$ heterojunction LED by microwave-assisted chemical bath deposition," Superlattices and Microstructures, vol. 53, pp. 31-38, 2013.

[5] J. Hüpkes, B. Rech, O. Kluth et al., "Surface textured MFsputtered $\mathrm{ZnO}$ films for microcrystalline silicon-based thinfilm solar cells," Solar Energy Materials and Solar Cells, vol. 90, no. 18-19, pp. 3054-3060, 2006.

[6] S. J. Ippolito, S. Kandasamy, K. Kalantar-Zadeh et al., "Highly sensitive layered $\mathrm{ZnO} / \mathrm{LiNbO}_{3} \mathrm{SAW}$ device with $\mathrm{InO}_{x}$ selective layer for $\mathrm{NO}_{2}$ and $\mathrm{H}_{2}$ gas sensing," Sensors and Actuators $B$, vol. 111-112, pp. 207-212, 2005.

[7] M. Bender, E. Gagaoudakis, E. Douloufakis et al., "Production and characterization of zinc oxide thin films for room temperature ozone sensing," Thin Solid Films, vol. 418, no. 1, pp. 45-50, 2002.

[8] N. D. Khoang, H. S. Hong, D. D. Trung et al., "On-chip growth of wafer-scale planar-type $\mathrm{ZnO}$ nanorod sensors for effective 
detection of CO gas," Sensors and Actuators B, vol. 181, pp. 529536, 2013.

[9] M. Z. Ahmad, J. Chang, M. S. Ahmad, E. R. Waclawik, and W. Wlodarski, "Non-aqueous synthesis of hexagonal $\mathrm{ZnO}$ nanopyramids: gas sensing properties," Sensors and Actuators $B$, vol. 177, pp. 286-294, 2013.

[10] T. T. Trinha, N. H. Tuc, H. H. Lec et al., "Improving the ethanol sensing of $\mathrm{ZnO}$ nano-particle thin films-the correlation between the grain size and the sensing mechanism," Sensors and Actuators B, vol. 152, pp. 73-81, 2011.

[11] C. S. Prajapati and P. P. Sahay, "Alcohol-sensing characteristics of spray deposited $\mathrm{ZnO}$ nano-particle thin films," Sensors and Actuators B, vol. 160, no. 1, pp. 1043-1049, 2011.

[12] H. M. Aliha, A. A. Khodadadia, and Y. Mortazavi, “The sensing behaviour of metal oxides $\left(\mathrm{ZnO}, \mathrm{CuO}\right.$ and $\left.\mathrm{Sm}_{2} \mathrm{O}_{3}\right)$ doped$\mathrm{SnO}_{2}$ for detection of low concentrations of chlorinated volatile organic compounds," Sensors and Actuators B, vol. 181, pp. 637643, 2013.

[13] Z. Lin, C. Guo, Q. Fu, and W. Song, "Abnormal photoelectrical properties and gas sensing of mesoporous $\mathrm{Sn}_{0.9} \mathrm{Ti}_{0.1} \mathrm{O}_{2}$ film under UV light," Materials Letters, vol. 102-103, pp. 47-49, 2013.

[14] M. H. Mamat, N. N. Hafizah, and M. Rusop, "Fabrication of thin, dense and small-diameter zinc oxide nanorod array-based ultraviolet photoconductive sensors with high sensitivity by catalyst-free radio frequency magnetron sputtering," Materials Letters, vol. 93, pp. 215-218, 2013.

[15] L. Luo, B. D. Sosnowchik, and L. Lin, "Local vapor transport synthesis of zinc oxide nanowires for ultraviolet-enhanced gas sensing," Nanotechnology, vol. 21, no. 49, Article ID 495502, 2010.

[16] S. W. Fan, A. K. Srivastava, and V. P. Dravid, "UV-activated room-temperature gas sensing mechanism of polycrystalline ZnO," Applied Physics Letters, vol. 95, Article ID 142106, 2009.

[17] C. Soci, A. Zhang, B. Xiang et al., "ZnO nanowire UV photodetectors with high internal gain," Nano Letters, vol. 7, no. 4, pp. 1003-1009, 2007.

[18] L. Luo, Y. Zhang, S. S. Mao, and L. Lin, "Fabrication and characterization of $\mathrm{ZnO}$ nanowires based UV photodiodes," Sensors and Actuators A, vol. 127, no. 2, pp. 201-206, 2006.

[19] D. Yuvaraj and K. N. Rao, "Selective growth of $\mathrm{ZnO}$ nanoneedles by thermal oxidation of $\mathrm{Zn}$ microstructures," Materials Science and Engineering B, vol. 164, no. 3, pp. 195-199, 2009.

[20] M. R. Khanlary, V. Vahedi, and A. Reyhani, "Synthesis and characterization of $\mathrm{ZnO}$ nanowires by thermal oxidation of $\mathrm{Zn}$ thin films at various temperatures," Molecules, vol. 17, pp. 50215029, 2012.

[21] Q. Xu, R. Hong, H. Huang, Z. Zhang, X. Chen, and Z. Wu, "Enhanced band-gap emission in ZnO Nanocaves by two-step thermal oxidation Zn film," Materials Letters, vol. 91, pp. 139141, 2013.

[22] N. Barsan and U. Weimar, "Conduction model of metal oxide gas sensors," Journal of Electroceramics, vol. 7, no. 3, pp. 143-167, 2001.

[23] J. L. Zhao, X. M. Li, A. Krtschil et al., "Study on anomalous high p-type conductivity in $\mathrm{ZnO}$ substrate prepared by ultrasonic spray pyrolysis," Applied Physics Letters, vol. 90, Article ID 062118, 2007.

[24] S. S. Lin, "Robust low resistivity p-type ZnO:Na films after ultraviolet illumination: the elimination of grain boundaries," Applied Physics Letters, vol. 101, no. 12, Article ID 122109, 2012. 

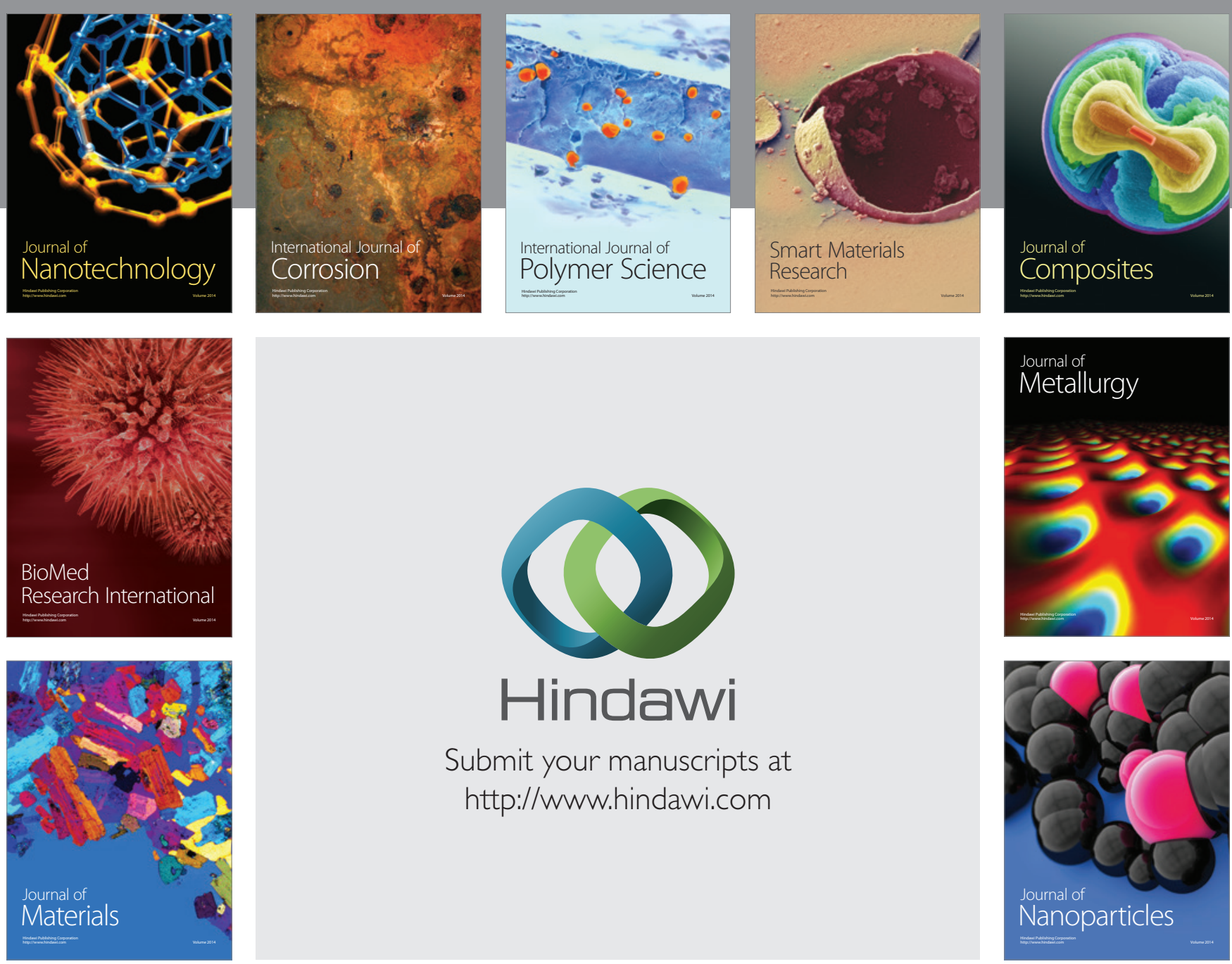

Submit your manuscripts at http://www.hindawi.com
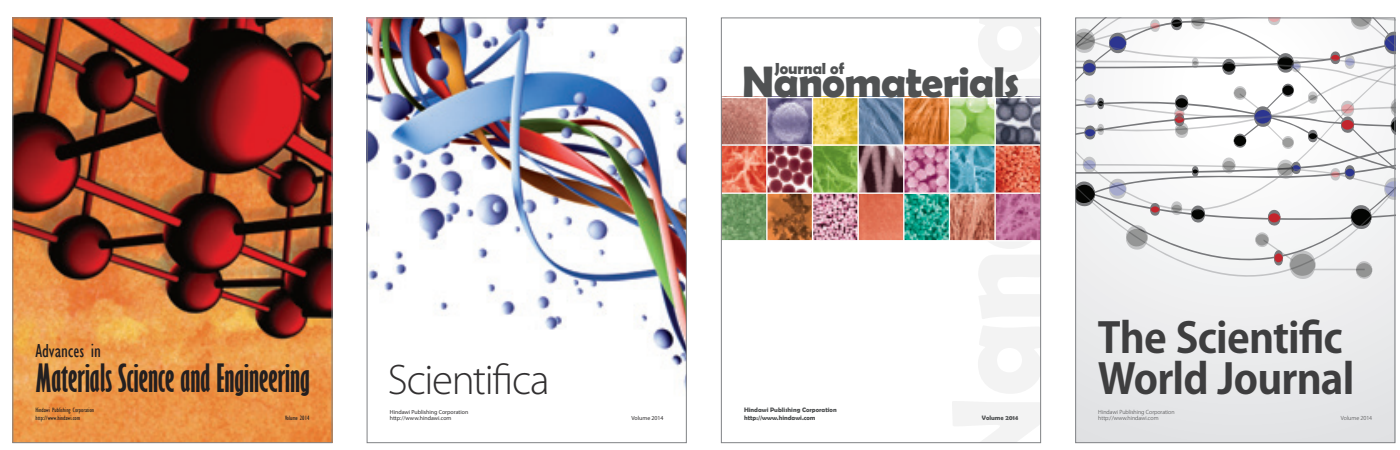

\section{The Scientific World Journal}
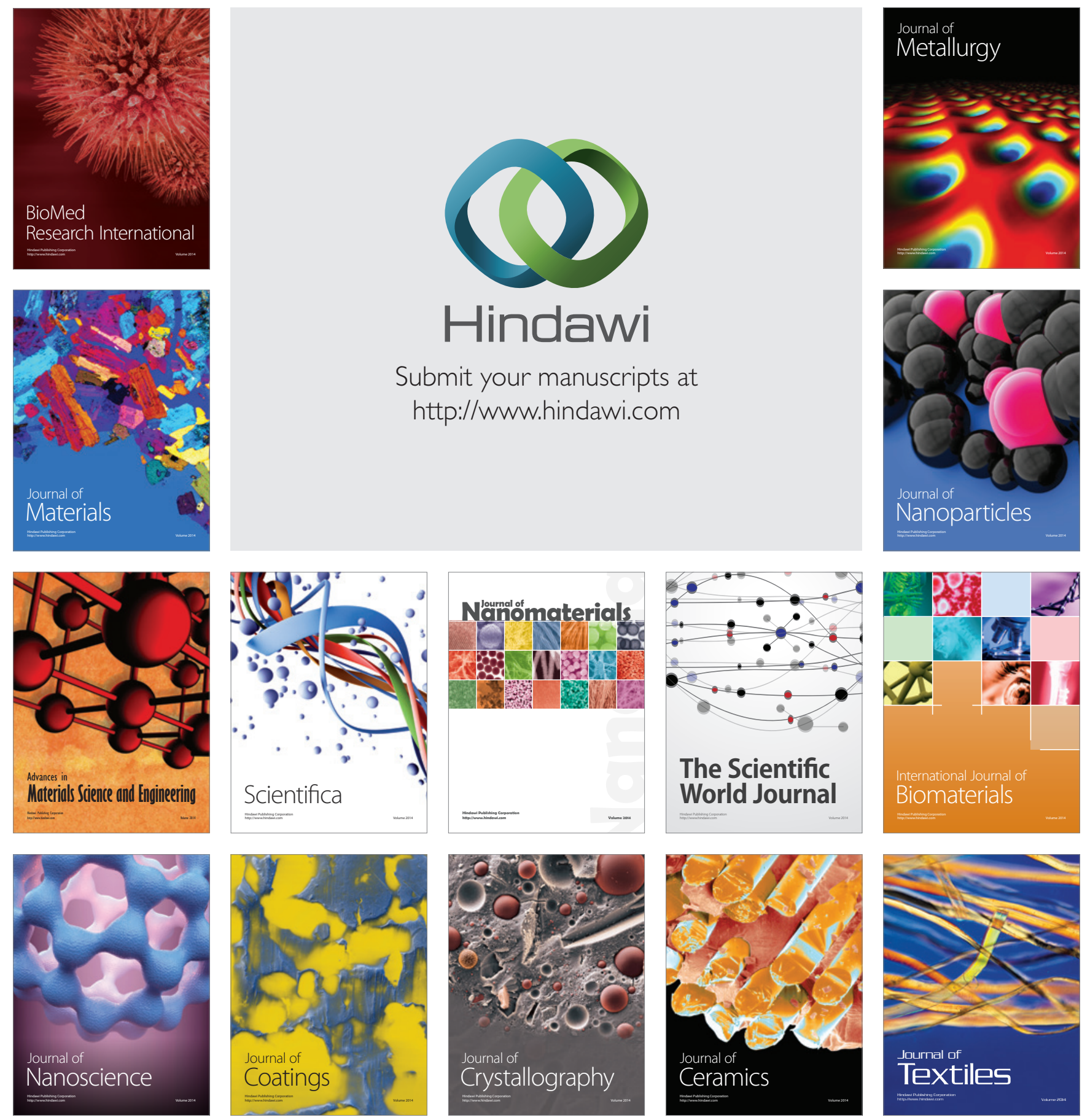